\title{
La caída del argumento de autoridad y el ascenso de la sana crítica*
}

\author{
Rodrigo Coloma Correa**
}

\begin{abstract}
RESUMEN
Este texto intenta responder a la interrogante de si la irrupción de la sana crítica ha provocado la desaparición -o al menos la declinación- del argumento de autoridad en el espacio de la valoración de la prueba. Aquello no es un asunto menor, pues las objeciones a su predecesora (la prueba tasada) se relacionaban, principalmente, con la insostenibilidad de operar en escenarios en que la fuerza de un argumento se biciera depender del prestigio de quien, en un momento dado, lo babia sostenido. Tras realizar precisiones conceptuales sobre el argumento de autoridad, de evaluar si es o no concebible prescindir de este en el contexto de la construcción de conocimientos, $y$ de analizar el beneficio que, en ocasiones, representa la inercia argumental, se concluye que el ascenso de la sana crítica no ha significado la total eliminación del argumento de autoridad. Este fenómeno no representa en sí un problema de racionalidad, bajo la condición de que lo dicho por la autoridad sea derrotable por eventuales versiones alternativas, mejor justificadas.
\end{abstract}

Argumento de autoridad - prueba tasada - sana crítica

\section{The fall of the argument from authority and the rise of sound criticism}

\begin{abstract}
This text tries to answer the question whether the irruption of sound criticism has lead to the disappearance -or at least the declination - of the argument from authority from the sphere of weighing evidence. This is not an irrelevant issue, since the objections to the previous system (legal proof) were related, mainly, with being untenable for operating in scenarios in which the force of an argument depended on the prestige of who, in a certain moment, had maintained it. After making some conceptual precisions to the argument from authority, evaluating if it is or not conceivable to disregard it from the construction of knowledge, and analysing the benefit that represents, sometimes, argumental inertia, the conclusion is that the rise of sound criticism has not mean the complete elimination of the argument from authority. This phenomenon does not imply by itself a problem of rationality, under the condition that what is maintained by the authority can be defeated by possible alternative versions better justified.
\end{abstract}

Argument from authority - legal proof - sound criticism

* Este trabajo corresponde a resultados del Proyecto financiado por el Fondo Nacional de Desarrollo Científico y Tecnológico, FONDECYT N 1110409 "La construcción de lo probado en los procesos judiciales. Vaivenes entre la ciencia, la lógica, el sentido común y la íntima convicción del juzgador”.

** Doctor en Derecho, Profesor adjunto de las facultades de Derecho de las universidades Alberto Hurtado y Católica de Temuco. Correo electrónico: rcoloma@uahurtado.cl. Dirección postal: Cienfuegos 41, Santiago de Chile.

Artículo recibido el 30 de agosto de 2012 y aceptado para su publicación por el Comité Editorial el 26 de octubre de 2012. 
«Los profesores de Harvard no cometen asesinatos». Esto fue lo que testimonió a favor de Webster el entonces presidente de Harvard, que subió al estrado inmediatamente antes que el doctor Holmes.

Matthew Pearl. El Club Dante ${ }^{1}$.

\section{INTRODUCCIÓN ${ }^{2}$}

$\mathrm{L}$ a arremetida de prominentes figuras de la Ilustración en contra del exagerado protagonismo que había tenido el legislador ${ }^{3}$ en el espacio de la valoración de la prueba, implicó asestar un duro golpe al sistema de la prueba tasada del cual no ha podido reponerse hasta nuestros días ${ }^{4}$. Los efectos de este ataque pregonado desde el prestigioso campo de la razón, se hicieron visibles en el repliegue de numerosas directivas jurídicas que, hasta ese entonces, forzaban a los jueces a validar solo aquellos relatos que cumplían con las condiciones prefijadas por la autoridad, como también, en la (re) aparición de mecanismos de valoración de la prueba que ampliaban considerablemente la discrecionalidad otorgada a los tribunales de justicia. Los planteamientos de los filósofos, por cierto, no obedecían a una preocupación que estuviese circunscrita a la forma de operar en los sistemas de enjuiciamiento prevalecientes en aquella época, sino que correspondía a una de las varias aristas de una nueva forma de concebir la construcción del conocimiento en distintos ámbitos de la vida. En pocas palabras, el conocimiento pasaba a ser mucho menos dependiente de la influencia de los autores clásicos y como contrapartida, debía ajustarse estrechamente a lo que era exigible desde teorías experimentalmente validadas.

La irrupción de la sana crítica -en cuanto sistema de valoración de la prueba que no da cabida a que las reglas legales sean las que determinen las conclusiones a las que los jueces están forzados a arribar a partir de la información disponible- constituye un fenómeno que se relacionaría con lo indicado en el párrafo precedente. Bajo esta nueva forma de comprender la fijación de los hechos en las sentencias, el acento deja de estar situado en lo que diga la autoridad legislativa, desplazándose, aparentemente, hacia algunas virtudes epistémicas practicables en el contexto de los procesos judiciales o, lo

${ }^{1}$ Pearl, M., El Club Dante, Seix Barral, Barcelona, 2006, p. 72.

${ }^{2}$ Un borrador de este trabajo fue discutido en el Seminario3 de la U. Alberto Hurtado. Los comentarios estuvieron a cargo de Cristóbal Joannon L. y Jorge Larroucau T. a quienes agradezco especialmente sus indicaciones. Los errores que perduran, huelga decirlo, son responsabilidad mía.

${ }^{3}$ En rigor, las reglas de valoración de la prueba no eran un producto exclusivamente legislativo, sino que, en una importante medida, eran creadas por la doctrina. Ver Taruffo, M. La prueba de los hecho, Trotta, Madrid, 2000, p. 389.

${ }^{4}$ Ver, a modo de ejemplo, Beccaria, C., Tratado de los delitos y las penas, $2^{\mathrm{a}}$ ed., Rosa Librero, París, 1828, pp. 46-49 y el Comentario sobre el libro Tratado de los delitos y las penas de Voltaire en la misma obra p. 284-286. La reacción ilustrada en contra del sistema de la prueba no fue unitaria, ver Montesquieu, C. Del espíritu de las leyes (libro VI, cap. XVII), Tecnos, Madrid, 1985, p. 67. 
que vendría siendo lo mismo, hacia mecanismos racionales de validación de hechos en los juicios 5 . Otra forma de plantear esto $-y$ que resultará útil para la articulación de lo que a continuación será desarrollado- apunta que no es una coincidencia la relativa simultaneidad que se da entre el creciente éxito de la sana crítica y la declinación experimentada por el argumento de autoridad (o de apelación a la autoridad), en aquellos ámbitos en los cuales se aspira a producir conocimientos intersubjetivamente validados.

En lo que sigue, intentaré hacer algunas precisiones respecto de si resulta o no aconsejable una total desaparición del argumento de autoridad (en adelante, también AA) en el contexto de la fijación de los hechos en los procesos judiciales y, junto a ello, si la sana crítica ha supuesto realmente la desaparición del AA.

\section{Algunas precisiones aCerCa Del poder De las Disciplinas}

En los tiempos que corren, la madurez (y/o prestigio) de las disciplinas supone que la validez de sus enunciados no se haga depender de la fama de quienes los hayan formulado, sino de la adecuada aplicación de formas procedimentales reconocidas, ya sea para los efectos de proponer nuevos conocimientos, o bien para eliminar a aquellos que han ido cayendo en obsolescencia. Lo señalado parece de toda lógica, pues la sola circunstancia de que alguien diga o niegue algo no añadiría un ápice de verdad, corrección, justicia o conveniencia al mensaje comunicado ${ }^{6}$.

En un escenario como el aludido, las sospechas que recaen sobre los $\mathrm{AA}^{7}$ llevan a que las disciplinas se esfuercen por depurar aquellos procedimientos que produzcan enunciados cuya función es la de representar la realidad ${ }^{8}$. Si aquello fuere logrado, las disciplinas estarán en condiciones de reclamar para sí la exclusividad de ciertos territorios del conocimiento, pudiendo beneficiarse de esta especialización, incluso quienes no sean sus cultivadores directos, por la vía del progreso técnico y la solución de enigmas ${ }^{9}$. Al contrario -aunque de hecho no siempre ocurra así- las disciplinas deberán estar dispuestas a renunciar a su hegemonía en aquellos espacios en que sus logros resulten todavía

${ }^{5}$ El carril por el cual corre la íntima convicción es diferente, ya que -al menos en alguna de sus vertientes- puede ser asociado a una aproximación escéptica respecto de la construcción de conocimientos intersubjetivamente controlables.

${ }^{6}$ Popper K., La lógica de la investigación científica, Tecnos, Madrid, 1967 (reimpresión de la 1ª edición de 1962), p. 45. Lo expresado por Popper no es un asunto exento de polémica. Ver desarrollos recientes relacionados a los límites de la racionalidad del desacuerdo. Feldman, R. "Evidentialism, higher-order evidence", en Episteme, 2009, p. 294 y ss.

${ }^{7}$ Ver Tindale, C., "La falacia y la apelación a la autoridad”, en Santibáñez, C., Marafioti, R. (eds.), De las falacias: argumentación y comunicación, Biblos, Buenos Aires, 2008, pp. 155-158.

${ }^{8}$ Según Rorty, la posición dominante enfatiza que el mayor estatus que alcanza una disciplina se hace depender de su reconocimiento como metódica. Rorty, R., "La ciencia como solidaridad", en Íd., Objetividad, relativismo y verdad. Paidós, Barcelona, 1996, pp. 58-59.

${ }^{9}$ Sobre la aceptación de enunciados que pueden resultar incomprensibles para quienes no cultivan una disciplina ver Ullmann-Margalit, E., Margalit, A. "Holding true and holding as true", en Synthese, Vol. 92, 1992, p. 167. 
precarios, abriéndose de esa manera a la posibilidad a ser colonizadas por el sentido común o, mejor aún, por otros expertos.

Es posible que parte del éxito alcanzado por el modelo newtoniano se haya debido a su renuncia deliberada a entrometerse en todos los espacios de nuestras vidas. La ciencia autorrestringió su influencia únicamente a aquellos ámbitos en que se encontraba suficientemente preparada como para proveernos de buenas respuestas a los enigmas que le eran planteados. Entre la verdad y el bien, que hasta ese entonces eran gobernados por la filosofía y la teología, la ciencia optó por la verdad y entregó el problema del bien a otras disciplinas ${ }^{10}$.

Cuando una disciplina alcanza un nivel de desarrollo que le lleva a ser reconocida como proveedora preferente (o exclusiva) de respuestas a problemas que se presentan en un cierto dominio de la vida - sin necesidad de que quienes las reciban se vean forzados a escrutar cada una de sus proposiciones según los conocimientos disponibles para el ciudadano común- podrá institucionalizar los espacios de la argumentación. Esto significa que puede imponer a sus miembros algunos puntos de partida en sus discusiones, los cuales se situarán bastante más allá de lo que sería normal (si es que de lo que se tratare fuere un simple ejercicio de argumentación entre legos) ${ }^{11}$. Una consecuencia evidente de ello es que la argumentación se irá haciendo más eficiente (no hay que discutirlo todo) y por tanto, sus miembros estarán en condiciones de dar respuestas a un mayor número de asuntos.

Lo expresado no evita que las disciplinas más consolidadas estén liberadas de caer en desgracia. En ese orden de cosas, no debiera extrañar que las ciencias, especialmente desde las postrimerías del siglo XX, hayan tenido que soportar críticas en razón del debilitamiento de dos de sus supuestos claves para que se les respetare y aceptare, en cuanto "comunidad de expertos que habla más o menos con una única voz". Aquellos supuestos, al decir de Immanuel Wallerstein, referían a que los expertos se capacitaban de manera prolongada y rigurosa en instituciones que los avalaban y dentro de lo posible, no respondían a sus intereses personales ${ }^{12}$.

$$
* * *
$$

${ }^{10}$ Wallerstein, I., Las incertidumbres del saber, Gedisa, Barcelona, 2004, pp. 28-29.

${ }^{11}$ Eemeren, F. v., Houtlosser, P., "Más sobre falacias como descarrilamientos de maniobras estratégicas: el caso de tu quoque”, en Santibáñez, C., Marafioti, R. (eds.), De las falacias: argumentación y comunicación, Biblos, Buenos Aires, 2008, pp. 43-46.

12 Wallerstein, I., Las incertidumbres del saber, Gedisa, Barcelona, 2004, p. 17. Es interesante observar que Alex Stein al reconstruir las razones invocadas por los defensores de la prueba libre en los procesos judiciales, alude a los mismos supuestos aquí señalados, los cuales tampoco se sostendrían en los tiempos actuales. Stein, A., “Against free proof”, en Israel Law Review, Vol. 31, 1997, pp. 577 y ss. 
Como comunidad especializada, los abogados han llegado a construir un discurso, por regla general, bastante sofisticado en lo que refiere a identificación e interpretación de textos normativos. Esta circunstancia se ha reflejado en que entre sus distintos miembros regularmente se producen niveles elevados de consenso acerca de si una determinada forma de entender, por ejemplo, el artículo de una ley o la cláusula de un contrato, se encuentra o no correctamente justificada ${ }^{13}$. Entre los distintos efectos que de ello se derivan puede destacarse el hecho de que, por regla general, quienes no pertenecen a la disciplina se verán forzados a reconocer que no dominan ni el método ni el vocabulario requerido para discutir con los abogados en igualdad de condiciones. Así las cosas, deben rendirse ante lo que los expertos dicen en su campo disciplinario, incluso si no entienden suficientemente qué es lo que han querido decir, o bien cómo se ha justificado una determinada aserción. En consecuencia, si algún foráneo pretende desafiar seriamente lo que sostiene la dogmática jurídica asentada deberá apoyarse en otros abogados que le suministren saberes especializados y modelos acerca de cómo hacer las cosas; ello en la búsqueda de poder argumentar en una situación de relativa simetría (lo que de todas formas, resultará difícil de lograr).

La posición de los abogados y de los jueces resulta, en cambio, bastante más inestable cuando les toca moverse en el espacio de la fijación de los hechos (o construcción de lo probado). Tanto en lo que refiere a la pesquisa de las pruebas relevantes en un caso concreto, como en la atribución de valor a piezas de información ya disponibles, los abogados carecen de un método lo suficientemente legitimado como para expulsar a los intrusos; más aún suelen necesitar del auxilio de estos para mejorar su performance. En otras palabras, los abogados no cuentan con ventajas en sus puntos de partida respecto de otros sujetos que no pertenecen a la disciplina si es que ellos contaren, por ejemplo, con un tiempo de formación equivalente en la universidad. Incluso más, los abogados se muestran en una posición de inferioridad frente a profesionales con saberes especializados en física, química, medicina, ingeniería o psicología, en varios de los asuntos que, de tarde en tarde, son discutidos ante los tribunales de justicia.

Para enfrentar el anunciado problema de debilidad disciplinaria -en lo que a valoración de la prueba se refiere- se ha optado por uno entre tres posibles caminos ${ }^{14}$. El primero (prueba tasada), supone expulsar (parcialmente) a los intrusos por la vía de establecer reglas capaces de derrotar a los métodos de producción de conocimientos que ellos pregonen, y de la mano de ello, estandarizar las respuestas posibles aplicando los puntos de vista fijados a priori por la autoridad legislativa. El segundo (íntima convicción),

${ }^{13}$ Desde la perspectiva trazada por Kuhn para dar cuenta de lo que ocurre en las ciencias, podría sostenerse que los abogados comparten una matriz disciplinaria (o paradigma) que incide en que una serie de asuntos fundantes de la disciplina no requieran ser problematizados para cada nuevo problema que se presente y, a la vez, que se institucionalice una cierta forma de hacer las cosas. Kuhn, Th., La estructura de las revoluciones científicas, $1^{\mathrm{a}}$ edición (16 a reimpresión), Fondo de Cultura Económica, Madrid, 1994.

${ }^{14}$ Los contornos de los distintos sistemas de valoración de la prueba son borrosos y admiten mezclas. En muchas ocasiones, podría hablarse de un sistema preferentemente de prueba tasada, íntima convicción, sana crítica o, incluso, de sistemas mixtos. 
implica sustraer la decisión de fijación de los hechos del espacio de la intersubjetividad y del control recíproco -que es reconocido por muchos como una condición básica del discurso racional- para abandonarse, en cambio, al punto de vista que en el caso concreto sea del gusto del decisor ${ }^{15}$. Es decir, aquí no se está practicando el mismo juego que en las disciplinas que aspiran a producir conocimientos socialmente validados, pues bajo este sistema la sola circunstancia de que un cierto sujeto (el juez) diga algo, resulta suficiente para atribuir valor a enunciados de naturaleza fáctica. En el tercer camino (sana crítica), se opta por abrir las puertas a los expertos de otras disciplinas e incluso al saber de los legos, para acto seguido aprovecharnos de sus resultados bajo el expediente de reconocerles el estatus de hechos en los procesos judiciales.

Retomando lo expresado algunas líneas atrás -en cuanto a que la ciencia ha elegido operar en el campo de la verdad y renunciado a inmiscuirse en el problema del bien-podría entenderse que la cultura jurídica al establecer, ya sea un sistema de íntima convicción o de sana crítica, opta porque su ámbito como experta se vea reducido a cuestiones de legalidad, o si se prefiere, de justicia. Sus respuestas como especialista se enfocarán entonces hacia el problema de qué es lo que debe hacerse (normatividad) y no hacia el asunto de cuál es el caso (facticidad). Sobre esto último se repliega, ya sea dando paso a las creencias del adjudicador (íntima convicción) o a sistemas de producción de conocimientos que cuentan con ciertos niveles de reconocimiento social (sana crítica).

En varios de los procedimientos judiciales aplicables en Chile -y en especial aquellos que han sido modificados en los últimos años- se ha optado por la tercera alternativa. Así, son escasas las restricciones a la admisibilidad de piezas de información que sirvan para fortalecer o debilitar los relatos en competencia y se han eliminado reductos, tanto de prueba tasada como de íntima convicción, en cuanto mecanismos autorizados para su valoración. El prudente reemplazante (la sana crítica), se remite eminentemente a la lógica, a los conocimientos científicamente afianzados y a las máximas de la experiencia, entendiendo que en su conjunto desempeñarán una función clave para conectar o bloquear conexiones entre los relatos propuestos por las partes (o, incluso, por los mismos jueces) con la información producida en el caso concreto.

Con la sana crítica se reconoce la distribución del trabajo de producir conocimientos, pues se da cabida a las aportaciones de otros más expertos e, incluso, a los depositarios del sentido común (los abogados, en cuanto tales, se reservan la exclusividad solo en el ámbito de la identificación e interpretación de textos jurídicos) ${ }^{16}$. Al instaurarse un

${ }^{15}$ Esto requiere introducir algunos matices, pues el sistema de valoración de la íntima convicción se asocia con frecuencia a la participación de jurados. En situaciones, así debiera llevarse a cabo un ejercicio deliberativo que apunta a limar desacuerdos y, por tanto, al menos dentro de la subcomunidad de los jurados del juicio concreto, si hay cabida para el control recíproco.

16 Por cierto, tal autorrestricción no necesariamente obedece a una conducta ideológicamente comprometida con la producción de conocimientos de buena calidad, sino que podría ser la resultante de 
sistema amplio de admisibilidad de información y, sobre todo al optarse por la sana crítica, el AA se bate en retirada.

\section{Sobre Éxitos y FRACASOS DEL ARGUMENTO DE AUTORIDAD}

El AA puede ser entendido como una clase de discurso en que, al menos, parte de su éxito -representado por el hecho que sus destinatarios adoptan ciertas creencias o toman determinadas decisiones- depende del prestigio o poder reconocido a su emisor originario o a quienes lo hacen suyo de segunda mano ${ }^{17}$. En otras palabras, si ante un auditorio cualquiera la fuerza argumental de un planteamiento $\mathrm{P}$ resulta distinta según si este ha sido formulado por un sujeto $\mathrm{X}$ o por uno $\mathrm{Y}$, estaremos en presencia de un $\mathrm{AA}^{18}$. Pese a tratarse de una forma de argumentar que, a menudo, es blanco de apasionadas críticas $^{19}$, apelar a la autoridad de quien ha formulado cierto enunciado (ya sea de manera originaria o derivada) constituye un recurso eficaz para convencer a un auditorio de que lo que se está diciendo merece ser tenido en especial consideración, a los efectos de forjar una creencia o de tomar una decisión.

La fortuna que antaño alcanzó la prueba tasada -la que fácilmente puede ser reconstruida como una forma de AA- no es explicable solo por un problema de ineptitud de los jueces medievales para fijar hechos de una manera intersubjetivamente aceptable. Como ha señalado L. J. Cohen y otros ilustres autores, dicho sistema de prueba calzaba perfectamente con el tipo de "epistemología popular de la Edad Media tardía y del Renacimiento”. El sistema científico era cerrado, el conocimiento no era considerado como probabilístico ni susceptible de avances. Las fuentes del conocimiento científico descansaban en la autoridad de la Iglesia, de los grandes pensadores de la Antigüedad Clásica o en algunas tradiciones ${ }^{20}$. En otras palabras, el AA campeaba a sus anchas.

un acto prudente en cuanto a que si no se da ese paso, las sentencias judiciales perderán progresivamente su impacto para ir cediendo a otras formas de gestión de controversias.

${ }^{17}$ Esta forma de reconstrucción del AA, claramente, es mucho más débil que aquella que proveería una fórmula estrictamente ceñida a las exigencias de la lógica formal, como sería, "Todo lo que diga X es verdad. X dijo que P. Entonces, P”. Este planteamiento sin salirse todavía de la lógica formal, incluso, podría reducirse a un campo específico del conocimiento dominado por X. Hamblin, C. L., Fallacies, Vale Press, Virginia, 1970, p. 218.

${ }^{18}$ En estricto rigor, el problema de la fuerza del argumento podría estar influida por lo opuesto al $A A$, que tendría que ver con que a un sujeto se le atribuye un menor reconocimiento que a los sujetos que se encuentran en un punto de vista medio en la escala del prestigio.

${ }^{19}$ Ver Sokal, A. "El relativismo cognitivo en la filosofía de la ciencia", en Íd. Más allá de las imposturas intelectuales. Paidós, Barcelona, 2009, pp. 237-238.

${ }^{20}$ Cohen, L. J., "Freedom of proof", en Twining, W., Stein A. (eds.) Evidence and Proof. Darmouth, Aldershot, 1992, pp. 8-9. Ver también Cappelletti, M. El proceso italiano en el cuadro de la contraposición "civil law" - "common law" len/ Íd. Proceso, ideologías, sociedad. Buenos Aires: E.J.E.A., 1974, p. 315-361, p. 336; 
Habida cuenta de que las formas de producción de conocimientos más reconocidas en la actualidad suponen la aplicación de controles que dejan en permanente suspenso el otorgamiento del estatus verdadero de sus enunciados (a la espera de mejores explicaciones que podrán provenir desde el campo de la experimentación o de la aplicación de algoritmos), cabe preguntarse si ¿es absurda la pervivencia del AA en sociedades democráticas?, o lo que vendría siendo lo mismo, ¿se trata solo de un asunto de dominación de quienes (justa o injustamente) se encuentran en las partes más altas de la escala del saber o del poder? La respuesta debiera ser, en principio, negativa si es el caso de que se contare con buenas razones para tomarse en serio lo que es afirmado por parte de quienes en el pasado han demostrado rigurosidad y buen juicio, como también, si habiéndose levantado sospechas respecto de la validez de que se dice, se está dispuesto a exigir contrastaciones similares a las que serían exigibles a quienes no reconozcamos como autoridad $^{21}$.

El AA hace posible operar con un nivel mayor de inercia ${ }^{22}$ argumental que el que se da cuando se interactúa con sujetos que no son reconocidos como altamente creíbles, agudos o sabios. El AA permite la división del trabajo, ya que nos evita tener que investigar y analizarlo todo, si de lo que se trata es de construir o modificar creencias. Así, por ejemplo, el hecho de que cierta afirmación sea atribuible a Einstein, Gandhi o Rawls -o, más modestamente, al párroco al que gustamos escuchar en las misas dominicales o al comentarista radial que nos hace más llevadero la congestión vehicular camino al trabajo- instará al auditorio a aceptarlo sin mayores precauciones. Esto no es -prima facie- señal de irracionalidad, ya que permite dar por cerrados ciertos temas con no poca tranquilidad y poder abocarnos a otro tipo de asuntos que también nos interesan ${ }^{23}$.

En el día a día, el AA es muy útil, pues con frecuencia carecemos del tiempo, dinero y capacidad para llevar a cabo un ejercicio intelectual sofisticado que se enfile hacia la comprensión de todos los asuntos que nos preocupan. Así que el médico me haya dicho que tengo psoriasis es una razón para que yo entienda que las manchas rojas en mi piel son producidas por dicha enfermedad, como también que para mitigar sus efectos deberé tomar el medicamento que me ha recomendado. Por su parte, que el mecánico sostenga que el automóvil X es más seguro que el automóvil Z, es una razón para que en iguales condiciones prefiera comprar el automóvil X por sobre el automóvil Z o simplemente que crea que $\mathrm{X}$ es más seguro que Z (y si fuere

Giuliani, A., Il concetto de prova, Dott. A. Giuffrè Editore, Milano, 1961, p. 185 y ss.; y Hacking, I., The emergence of probability, Cambridge University Press, 1975, pp. 31-48.

${ }^{21}$ En estricto rigor las exigencias que habría que hacer recaer al AA para considerarlo, sin más como un mecanismo plenamente racional de producción debieran ser más fuertes que lo que aquí se señala. Sobre esto volveré a propósito de la distinción entre AA débiles y fuertes.

22 Ver Alexy, R., Teoría de la argumentación jurídica. La teoría del discurso racional como teoría de la argumentación jurídica. Centro de Estudios Constitucionales, Madrid, 1989, pp. 170-171; Eco, U., Seis paseos por los bosques narrativos, Lumen, Barcelona, 1996, p. 11.

${ }^{23}$ Cfr. Toulmin, S., Los usos de la argumentación, Península, Barcelona, 2007, p. 29. 
el caso, así lo llegaré a declarar ante terceros). El argumento será de autoridad en la medida en que yo como destinatario no me encuentre en posición de refutar lo que ha sido dicho (por ejemplo, no soy capaz de identificar un caso de psoriasis), o incluso teniendo las competencias para hacerlo, no me encuentro interesado en llevar a cabo tal ejercicio de comprobación ${ }^{24}$.

El AA, sin embargo, es peligroso sobre todo porque hay ocasiones en que va aparejado al otorgamiento de una importante cuota de poder sobre quienes son reconocidos como sabios, expertos o dotados de buen criterio, más allá si en el caso concreto cuentan con buenas razones que sirvan de soporte a sus afirmaciones ${ }^{25}$. El AA trae consigo una renuncia por anticipado a participar en un ejercicio deliberativo cuya consecuencia posible será la modificación de creencias o decisiones. Así las cosas, el AA debe ser administrado con bastante cuidado. En ocasiones, incluso, podrá operar como un planteamiento ad hoc que permite al sujeto a quien se le reconoce el estatus de autoridad ir adaptándose a sus intuiciones o preferencias, según sea el caso al que está enfrentando. Eso no es lo que esperamos de los jueces. El problema será entonces, cuándo los argumentos que descansan en la experticia de quienes los formulan son razonables y cuándo, falaces ${ }^{26}$.

En el mundo de la adjudicación el AA encuentra un terreno fértil para operar, pues el éxito de la ideología según la cual los jueces deben limitarse a aplicar reglas preexistentes constituye un importante acicate para atribuir valor a cualquier argumento que potencie la creencia de que la subjetividad del juzgador no influyen en que un cierto litigio se haya resuelto en un sentido u otro (ojalá que "los hechos hablen por sí solos")27. En este escenario, si existe una autoridad en la configuración del conocimiento (perito), entonces el juez -que no cuenta con saberes especializados, por ejemplo, en química o genética y que, para colmo de males, no estuvo en el lugar del crimen- no gustará de apartarse de lo que dicen quienes se encuentran en una posición privilegiada en la escala de reconocimiento de la producción de saberes.

${ }^{24}$ Ver Downs, A., An economic theory of democracy, Harper \&Row Publishers, New York, 1957, p. 222 y ss. (especialmente, p. 233).

25 Así, se habla de que el "conocimiento es poder" y aquello se hace en distintos niveles (filosofía, textos sagrados, etc.). Ver, por ejemplo la entrada Scientia potentia est en Wikipedia (inglés) http://en.wikipedia. org/wiki/Scientia_potentia_est Última visita 20 de agosto de 2012.

26 Walton, D., "Reasoned use of expertise in argumentation”, en Argumentation, 3, 1989, p. 60. Desde hace algún tiempo el estudio de las falacias las ha concebido más como "movimientos incorrectos en el discurso argumentativo", antes que como "argumentos que parecen válidos pero que en realidad no lo son”. Eemeren, F. v., Houtlosser, P., "Más sobre falacias como descarrilamientos de maniobras estratégicas: el caso de tu quoque”, en Santibáñez, C., Marafioti, R. (eds.), De las falacias: argumentación y comunicación, Biblos, Buenos Aires, 2008, p. 37.

27 Por cierto, las cosas no son así. Jorge Larroucau, por ejemplo, analizando la jurisprudencia del art. 2329 del Código Civil demuestra precisamente que son los jueces los que hablan, no la cosa (los jueces crean conocimiento a partir de la ignorancia). Larroucau, J. "Res ipsa loquitur: Quien habla es el juez, no la cosa”, en Figueroa, G., Barros, E., Tapia, M. (coords.), Estudios de Derecho Civil VI, LegalPublishing, Santiago, 2011, pp. 491 y ss. 


\section{IV. ¿EL ASCENSO DE LA SANA CRÍTICA HA PROVOCADO LA CONSIGUIENTE DESAPARICIÓN DEL AA EN LA ETAPA DE VALORACIÓN DE LA PRUEBA?}

A pesar de que en las primeras líneas de este texto sostuve que la proscripción de la prueba tasada representó un duro golpe para la pervivencia del AA en el espacio de fijación de los hechos, es dudoso que este haya desaparecido del todo, al menos si se toma el caso de la sustitución de dicho sistema de valoración de la prueba por el de la sana crítica. El asunto que al respecto interesa no tiene que ver con la tendencia a aferrarse a viejas prácticas ${ }^{28}$, sino que se relaciona con la imposibilidad de fijar hechos en contextos en que se está autorizado a dudar de todo y, en forma indefinida. En un escenario así, otorgar relevancia al prestigio de quienes hayan formulado determinadas afirmaciones -y siempre que se cuente con algunos resguardos- no parece del todo descabellado. A fin de cuentas, en toda representación del mundo debe haber alguien que, en último término, se haga responsable de las conexiones tendidas entre aquello que se da por probado (o que es reconocido con el estatus de hechos) y la siempre insuficiente, y a veces contradictoria, prueba disponible.

Lo anterior ha dado pie a agudas observaciones en cuanto a que hay algún grado de inconsistencia en las críticas que los científicos gustan de hacer respecto a todo aquello que buela a aceptación de textos o discursos (con pretensiones de representar la realidad) por el solo hecho de emanar de Aristóteles, San Agustín u otro afamado pensador. Si se mira con detención, las actuales comunidades de expertos (científi$\cos$ ), en su conjunto, juegan un rol equiparable al que antaño era asumido por las autoridades filosóficas o religiosas que proponían sus propias imágenes del mundo ${ }^{29}$.

Para salir de este atolladero propondré un par de distinciones acerca del papel que es desempeñado por las autoridades determinadoras de reglas (generalizaciones), cuando de ellas sea posible extraer conocimientos funcionales a la fijación de hechos en las sentencias judiciales ${ }^{30}$. La clasificación que realizaré será entre AA originarios y derivados, como también, entre fuertes y débiles.

${ }^{28}$ Por cierto hay también algo de ello si se analizan las prácticas judiciales. Ver, por ejemplo, Fuentes, C., "La persistencia de la prueba legal en la judicatura de familia", en Revista de Derecho de la Universidad Católica del Norte, Año 18, N¹, 2011, pp. 119-145.

${ }^{29}$ Immanuel Wallerstein explica que los partidarios de dicho cambio, por una parte, querían "negar el derecho de las autoridades religiosas y políticas a promulgar la verdad”, pues las ideas circulaban según las leyes del libre mercado, siendo la comunidad la que las aceptaba o rechazaba; y por la otra "creían que, salvo en raras excepciones, solo las personas que tuviesen una formación especializada en una materia tenían derecho a que se les tomara en serio cuando enunciaban sus verdades en el mercado de las ideas". Wallerstein, I., Las incertidumbres del saber, Gedisa, Barcelona, 2004, pp. 38-39.

${ }^{30}$ Ekelöf llama la atención que para los efectos de que la valoración de la prueba no sea considerada como un ejercicio de arbitrariedad (situación no deseable), la libre apreciación de la prueba está sometida a reglas legales, "aunque no en la misma forma que bajo la «doctrina de la prueba tasada»". Ekelöf, P., "Free Evaluation of Evidence”, en Scandinavian Studies in Law, 1964, Vol. 8, p. 48. 


\section{a) AA originarios y derivados}

A propósito del protagonismo, a veces, asumido por la prueba pericial en el espacio de la adjudicación, Renée Römkens da cuenta de desacuerdos acerca de la forma de evaluar si el poder es traspasado desde el legislador hacia los expertos (científicos) en los procesos judiciales. Por una parte, hay autores como Michel Foucault que consideran que el derecho habría ido perdiendo influencia respecto de algunas disciplinas que se han especializado en la comprensión de ciertas facetas del comportamiento humano, como ocurre con la psiquiatría ${ }^{31}$ (es decir, se estaría produciendo una declinación del AA, al menos cuando este proviene del legislador). Por la otra, hay autores que niegan que con la arremetida de los científicos, la autoridad normativa haya perdido poder en la determinación de lo probado. Al reconstruir este último punto de vista, dice Römkens: "Al final, las autoridades judiciales incluso deciden si y cuándo un sistema de saberes, que no sea el sistema de conocimiento jurídico, es relevante en un contexto jurídico”. Unas pocas líneas más adelante, ella añade: "(D)ado que los expertos científicos están comprometidos en un proceso epistemológico dentro de un contexto legal, la ley se fortalece como una institución cultural, en virtud de su facultad de calificar o descalificar, e incluir o excluir el conocimiento científico forense como (ir)relevante y/o verdadero"32.

La tensión planteada en el texto de Römkens -que pone sobre el tapete el problema de la identificación de la autoridad que efectivamente opera cuando el legislador reconoce en un tercero la potestad de extraer conclusiones fácticas traspasables a la sentencia- da pie a que se explore una posible distinción entre AA originarios y derivados. La condición de originario o de derivado con la que puede calificarse a los AA depende de si quien ejerce el poder ha establecido por sí mismo las conexiones que es válido realizar entre una o más piezas de información disponibles y ciertas conclusiones; o bien si ha delegado en un tercero dicha tarea. En el primero de los casos el AA será originario y en el segundo, derivado.

Lo señalado puede ser ilustrado con un ejemplo. Un niño de diez años se muestra intrigado porque la yegua en que cabalga parece advertir todos los movimientos que él va realizando. A raíz de ello, le pregunta a su padre si los caballos son capaces de ver a sus jinetes cuando están sobre su montura, recibiendo la siguiente respuesta: "los ojos de los herbívoros, a diferencia de los ojos de los carnívoros -que tienen una visión estereoscópica- no se encuentran situados frontalmente, lo cual

${ }^{31}$ Foucault sugiere que, al menos en el curso XIX la pericia médico legal invadía tanto a los tribunales como a la medicina. No pertenecía, propiamente, ni a uno ni a otro espacio, sino que adulteraba ambos. "La pericia médico legal no se dirige a delincuentes o inocentes, no se dirige a enfermos en confrontación a no enfermos, sino a algo que es creo la categoría de los anormales [...]”. Foucault, M., Los anormales, Fondo de Cultura Económica, Buenos Aires, 2011 ( $7^{\mathrm{a}}$ reimpresión), pp. 48-49.

${ }^{32}$ Römkens, R. "Ambiguous Responsibilities: Law and Conflicting Expert Testimony on the Abused Woman Who Shot Her Sleeping Husband”, en Mertz, E., The Role of Social Science in Law, Ashgate, Aldershot, 2008, pp. 402-403. 
incide en que prácticamente carezcan de un ángulo ciego. Si bien es cierto esto tiene ventajas (como poder observar a los depredadores ubicados a sus espaldas), los herbívoros son incapaces de captar la profundidad y, en consecuencia no ven en tres dimensiones". Si el hijo acepta la creencia que su padre le acaba de transmitir, pues supone que está bien informado, que no pretende engañarlo o incluso, está convencido de que él sabe todo, estaremos ante un AA originario. El niño, entonces, pasará a creer que si se sitúa detrás de cualquier herbívoro este lo podrá ver, como también se sentirá autorizado para transmitir a sus amigos la explicación de su padre (incluso reproduciendo aquella extraña locución "visión estereoscópica", que no sabe bien qué significa).

Pensemos ahora que el padre se abstiene de responder a la interrogante y le dice a su hijo que consulte a su tío que es veterinario, o bien, que investigue en Wikipedia. Si la aceptación de la explicación que le da su tío o Wikipedia se hace depender de que su padre le instó a consultarlos, estaríamos en presencia de un AA derivado. Esto último supone que, si el niño motu proprio hubiese consultado a esas fuentes de información, habría perseverado en sus dudas, a menos que lo escuchado o leído hubiese superado una rigurosa evaluación acerca de la calidad del contenido del texto o discurso.

\section{b) AA fuertes y débiles}

Es posible distinguir, también, entre AA fuertes y débiles. En el primero de los casos se trata de argumentos que difícilmente serán derrotados por planteamientos rivales, aun cuando estos últimos resultaren poderosos en contextos de diálogo racional. En los AA débiles, en cambio, el receptor del mensaje mantendrá su creencia o decisión en razón de haber sido afirmada por una autoridad sin necesidad de mayor escrutinio, a menos que se le presente un argumento rival que sea igual o más poderoso que el AA.

Retomemos el ejemplo del caballo e imaginemos que el niño ha leído un estudio de un grupo de científicos sobre una población de 50.000 caballos. Según este, los caballos podrían ver en tres dimensiones y su ángulo visual no sería tan amplio como hasta entonces se suponía. Si el niño siguiere creyendo sin alteraciones lo que le dijo su padre (o su tío o Wikipedia), el AA del padre debiera ser considerado como fuerte, pues no ha resultado derrotado por un argumento que, en principio, se presenta como más valedero. En cambio, será débil si evaluando estas nuevas piezas de información el niño está dispuesto a modificar sus creencias. Por cierto, si ante la sola afirmación de un tercero el niño suspende su creencia respecto de la visión de los herbívoros que su padre le propuso, no estaríamos ante un AA (lo que el padre dice vale lo mismo, independientemente de quien fuere su emisor).

El AA fuerte opera como una clase de argumento que no admite ser superado por otro, incluso si fuere el caso que evaluadas las distintas razones disponibles en favor de uno y otro punto de vista, se revelare como una peor explicación que la sugerida 
en la propuesta rival. Lo señalado no obsta a que podrá considerarse como fuerte aquel argumento que exija a sus rivales un estándar de corrección muy alto para llegar a ser derrotado. En ese sentido este argumento no necesariamente tendrá un estatus de razón absoluta o de argumento dogmático. El AA débil opera, en cambio, como una razón prima facie, esto es, admite ser considerado como una respuesta adecuada mientras no aparezca un punto de vista rival que cuente con más méritos para ser aceptado. Lo que le da el carácter de AA es que hace posible suspender la evaluación de los soportes del argumento, mientras no sea desafiado, esto es, admite recurrir a la inercia argumental ${ }^{33}$.

Para representar como opera la inercia argumental, considérese el caso de la sentencia dictada por un tribunal de familia:

"Decimotercero: [...] tanto la demandante como los testigos en forma reiterada aluden a la inmadurez de la actora para ejercer como madre y como cónyuge, lo que genera violencia en la familia. Cabe entonces preguntarse cómo no va a ser inmadura una adolescente de 14 años que debe asumir la maternidad y el matrimonio con un hombre de 25 años. La verdad es que así las cosas, no logró terminar sus estudios, los que hoy sí ha rendido, no se inserta en un mundo laboral y se genera una total dependencia. Entonces lo sensato no es aludir a la inmadurez, sino que verificar si existen boy las condiciones para asumir de buena forma la maternidad, lo cual conforme a la prueba pericial allegada la cual estima considerar a la actora como idónea para asumir el cuidado de su hija. Decimocuarto: Que asimismo también el informe pericial de la demandada sugiere considerar idónea a la referida para asumir el cuidado de su nieta. Es decir, ni la demandante ni la demandada presenta mejores habilidades parentales para detentar el cuidado personal de la niña, así como a su vez no presentan inhabilidades legales, a esto cabe sumar que la situación global de la madre no se aprecia desventajosa con relación a la de la abuela para llevar a cabo el cuidado personal.

En base a las conclusiones tácticas (sic) inamovibles expresadas en el párrafo anterior, se ha entonces de aplicar conforme a derecho la regla prevista en el artículo 225 del Código Civil, el cual otorga preferencia a la madre en lo relativo al cuidado personal, cuando los padres están separados, cuanto más entonces cuando la disputa no es entre los progenitores, sino que entre uno de los padres y un tercero".

En el considerando $13^{\circ}$, el tribunal desarrolla (o reproduce) una explicación a partir de lo que es señalado por los testigos; en cambio, en el considerando siguiente -que da cuenta de la prueba de un perito- se ha limitado a reproducir lo que este dijo. En este segundo caso, el tribunal ha operado bajo la inercia argumental, lo cual le

33 Esto tiene una similitud con la forma en que operan las razones excluyentes que hacen posible suspender la realización de un balance de todas las razones (de primer orden) que se encuentren disponibles. Raz, J., Razón práctica y normas, Centro de Estudios Constitucionales, Madrid, 1991, pp. 39-54. 
permitió liberarse (parcialmente) de proveer de soporte a sus conclusiones, en los mismos términos que lo había hecho en el considerando $13^{\circ}$.

\section{c) Combinaciones de propiedades que se adscriben a los AA y algunas consecuencias de ello}

A partir de las distinciones precedentes, es posible establecer cuatro clases de AA, esto es, originario - fuerte/originario débil/derivado fuerte/derivado - débil. Me referiré brevemente a cada uno de ellos, en el contexto de la valoración de la prueba, para luego extraer algunas conclusiones preliminares acerca de su compatibilidad con un sistema de sana crítica.

i. En los AA originarios-fuertes, el legislador establece directamente las conclusiones que pueden extraerse desde las piezas de información disponibles. Se trata de ejemplares que caen de lleno en el espacio de la prueba tasada y en consecuencia, no es pertinente señalar, en su caso, que se ha producido la declinación de los AA por el ascenso de la sana crítica. No se trata, por cierto, que la utilización de esta clase de AA conduzca necesariamente a soluciones opuestas a las esperables en escenarios en que lo único que importa es lo que podría llamarse la racionalidad epistémica ${ }^{34}$ : de hecho pudiere ser el caso de que haya altos niveles de coincidencia entre las respuestas provistas por ambos mecanismos de producción de conocimientos ${ }^{35}$. El asunto tiene que ver con que al operar esta clase de reglas la razón para extraer una determinada conclusión y no otra, a partir de la prueba rendida, se debe a que el legislador (la autoridad) así lo ha dicho. En la actualidad es posible encontrar reglas del sistema jurídico que entran en esta categoría, las que no necesariamente resultan comparables con las que, en su momento, fueron ásperamente criticadas por los ilustrados. Lo que, por regla general, se busca con ellas es implementar una cierta política pública y no resolver un problema de construcción de conocimientos en el contexto de los procesos judiciales.

Un ejemplo de esto puede advertirse en el artículo 201 del Código Civil al estipular que: "La posesión notoria del estado civil de hijo, debidamente acreditada, preferirá a las pruebas periciales de carácter biológico en caso de que haya contradicción entre una y otras.

Sin embargo, si hubiese graves razones que demuestren la inconveniencia para el hijo de aplicar la regla anterior, prevalecerán las pruebas de carácter biológico”.

Según es fácil intuir, el asunto no pasa porque el legislador considere que para la determinación de la paternidad (biológica) resulte más fiable la posesión notoria

${ }^{34}$ Ver Habermas, J., "Racionalidad del entendimiento. Aclaraciones al concepto de racionalidad comunicativa desde la teoría de los actos de habla”, en Íd., Verdad y justificación. Ensayos filosóficos, Trotta, Madrid, 2002, pp. 103-105.

${ }^{35}$ No hay que pensar que cuando el legislador opta por la prueba tasada se sienta liberado de operar bajo exigencias de racionalidad epistémica. Hacerlo representará un costo no menor en cuanto a la fuerza que podrá reconocerse a las reglas y/o a las decisiones que de su aplicación se extraigan. 
del estado de hijo que el examen de $\mathrm{ADN}$, sino porque es preferible adscribir el estatus de padre al sujeto que se comporte como tal, para así satisfacer ciertos valores (los menores deben estar a cargo de quienes demuestren afecto hacia ellos, etc.). Hay también ocasiones en que la regulación de las conclusiones extraíbles desde las pruebas permite, al mismo tiempo, resolver un problema de incertidumbre epistémica que el legislador no considera prudente dejar en manos de los jueces -bajo la sola restricción de respetar el estándar de prueba respectivo-, pues no se asegura una suficiente estandarización de las respuestas judiciales (esto podría ocurrir, por ejemplo, con la muerte presunta).

ii. En el caso de AA originarios y débiles, el legislador resuelve directamente un problema de validación de hechos o de relatos, por la vía de establecer las inferencias que el adjudicador está autorizado a realizar a partir de la prueba disponible. A diferencia de la situación anterior, el legislador deja de manera suficientemente explícita la posibilidad de que lo que él ha dispuesto, puede llegar a ser derrotado en el caso concreto. Se trata de argumentos prima facie, esto es que operan solo en caso de que lo que se extraiga de la regla estipulada por el legislador no se vea enfrentado a un rival de peso, desde el punto de vista epistémico. Por su estatus débil no se trata de implementar políticas públicas, sino de transmitir las preferencias del legislador respecto de la forma de construir conocimientos en el proceso judicial.

Un ejemplo lo podemos ver en el art. 456 del Código del Trabajo (cuyo contenido es también incorporado en otros textos legales). Se dice en este “[...] En general, [el tribunal] tomará en especial consideración la multiplicidad, gravedad, precisión, concordancia y conexión de las pruebas o antecedentes del proceso que utilice, de manera que el examen conduzca lógicamente a la conclusión que convence al sentenciador".

El juez, entonces, cuenta con la inercia argumental de no tener que justificar que la multiplicidad, gravedad, precisión, concordancia y conexión de las pruebas, constituyen razones para atribuir mayor fuerza a un cierto relato por sobre sus rivales. Con el uso de las locuciones "en general” y "tomará en especial consideración”, el legislador establece una autorización a los jueces para no seguir lo allí indicado. Esto no obsta a que en caso de que se produzca dicho alejamiento, haya expectativas de que en la sentencia respectiva se explique por qué el tribunal se apartó de lo sugerido por el legislador.

iii. En el caso de los AA derivados y fuertes, el legislador reconoce en una cierta comunidad (preferentemente disciplinaria) la facultad para determinar la validez (o la ausencia de esta) de una cierta explicación. Las conclusiones a las cuales se lleguen no resultarán derrotables, si es el caso de que se han seguido correctamente los protocolos asentados en la comunidad respectiva. Las razones para tal delegación podrán de carácter epistémico, si se reconoce que la referida comunidad se encuentra en condiciones de imponer ciertas representaciones del mundo en el ámbito de su experticia; o bien de 
carácter democrático o de reconocimiento cultural, si se hace permanecer dentro de la comunidad amplia la capacidad de imponer sus propias generalizaciones acerca de cómo conectar lo que se dará por probado y la información disponible.

Un ejemplo, puede verse en el artículo 199 del Código Civil. "Las pruebas periciales de carácter biológico se practicarán por el Servicio Médico Legal o por laboratorios idóneos para ello [...].

El juez podrá dar a estas pruebas periciales, por sí solas, valor suficiente para establecer la paternidad o la maternidad, o para excluirla [...]”.

iv. En el caso de los AA derivados y débiles existe, por parte del legislador, un reconocimiento de que hay una cierta comunidad (preferentemente disciplinaria) o sujetos específicos distintos a los jueces que ocuparán un lugar privilegiado en el análisis de la prueba disponible. Esto supone que, en igualdad de condiciones se deberán preferir aquellas explicaciones propuestas por los miembros de dichas comunidades, siendo posible derrotarlas si en el caso concreto se contare con explicaciones rivales que se hagan cargo en mejor forma de las particularidades del caso.

Dos ejemplos de ello, pueden encontrarse en:

Art. 23 del DFL N N $^{\circ}$, de 1967 (Orgánica de la Dirección del Trabajo): "Los Inspectores del Trabajo tendrán el carácter de ministros de fe respecto de todas las actuaciones que realicen en el ejercicio de sus funciones, dentro de las cuales podrán tomar declaraciones bajo juramento. En consecuencia, los hechos constatados por los Inspectores del Trabajo y de los cuales deban informar de oficio o a requerimiento, constituirán presunción legal de veracidad para todos los efectos legales, incluso para los efectos de la prueba judicial".

Art. 446 del Código Civil sobre interdicción por disipador: "Mientras se decide la causa, podrá el juez, a virtud de los informes verbales de los parientes o de otras personas, y oídas las explicaciones el supuesto disipador, decretar la interdicción provisoria”.

\section{d) La sana crítica como $A A$ derivado y débil}

Si se toman en cuenta algunas definiciones legislativas de la sana crítica en las cuales se destaca la prevalencia de la lógica, de los conocimientos científicos y de las máximas de la experiencia, por sobre la libertad de los jueces ${ }^{36}$, es posible extraer algunas conclusiones acerca de la incidencia que ella ha representado ya sea para la desaparición o para la pervivencia del $\mathrm{AA}^{37}$. Al remitirse a dichas fuentes de conocimiento, en un sistema

${ }^{36}$ Ver, en especial, el artículo 297 del Código Procesal Penal chileno y artículo 455 del Código del Trabajo.

${ }^{37}$ La remisión a estos sistemas de producción de conocimiento no es superflua, pues podría pensarse que si el legislador nada dijere el juez racional de todas formas debiera ceñirse a ellas. En algunos casos la 
puro $^{38}$ de sana crítica, el legislador se despoja de la potestad de establecer directamente las conexiones admitidas entre la prueba disponible y el discurso fáctico de la sentencia, pero no por ello deja de tomar posición acerca de qué es lo que deberá tener en cuenta el juez al tomar sus decisiones fácticas. En ese sentido, los AA que pudieran subsistir en el contexto de la sana crítica serían únicamente de carácter derivado. Algo más difícil es la determinación de si la sana crítica da pie tanto a AA fuertes como a débiles, o bien a solo uno de ellos. En principio, parece adecuado que el carácter de los AA en el caso de la sana crítica deba ser siempre fuerte, pues afirmar lo contrario significaría que la opinión del juez podría llegar a prevalecer por sobre lo que dice la lógica, la ciencia o las máximas de la experiencia, lo cual implicaría trasladarnos al espacio de la íntima convicción. Dicho punto de vista, sin embargo, se debilita desde el momento en que se reconoce que el juez inevitablemente conserva un ámbito de discrecionalidad cuando valora la prueba: no reconocerlo sería una ingenuidad asociada al sueño (o pesadilla) de encontrar explicaciones del comportamiento humano reducibles a la constatación de meras regularidades ${ }^{39}$. Al no existir relaciones ordenadoras entre los distintos sistemas de justificación recién mencionados (¿necesariamente prevalece la ciencia por sobre el sentido común, o debe ponerse atención al contexto?), al no existir fronteras claras, por ejemplo, entre lo que es científico y lo que no alcanza ese estatus (o entre lo que es de sentido común y lo que no lo es), e incluso al existir tensiones internas al interior de cada sistema de justificación (lo que lleva a arrojar respuestas diferentes ante asuntos similares), carecerá de sentido sostener que por la sola circunstancia de que al interior de uno de estos sistemas derivados se produzca cierta clase de conocimiento, la respuesta judicial pasa a estar determinada de manera fuerte.

Así, por ejemplo, cuando el conocimiento de experto que se incorpora en los juicios no es extraído desde lo que podría ser calificado como una disciplina dura, lo que se diga puede llevar a conclusiones totalmente opuestas a partir de pruebas similares. Esto lleva a que razones que no son propiamente epistémicas (o aceptables por la comunidad respectiva), terminan inclinando la balanza en uno u otro sentido ${ }^{40}$. Las disciplinas a las cuales remite el legislador no gobiernan, en términos fuertes, la

competición que se da, por ejemplo, entre el modelo de ciencia dominante y puntos de vista alternativos no es tan fácil de resolver, pues aquello supone tomar opciones que podrían tener una dimensión más valorativa que epistémica. Un problema de esta naturaleza puede verse en sentencia de la Corte de Apelaciones de Valdivia en sentencia Rol 103-2009, la cual puede ser revisada en comentario de Zúñiga, Y. "Medida de protección terapéutica a favor de un menor (sentencias del tribunal de familia y de la corte de apelaciones de Valdivia)", en Revista de Derecho de la Universidad Austral de Chile, Vol. XXII, No 1, julio de 2009, pp. 279-297.

${ }^{38}$ Es frecuente que en los procedimientos en los cuales se opta por la sana crítica se introduzcan reglas que lo combinan con prueba tasada o íntima convicción.

39 Sobre la situación de las ciencias sociales, ver Wallerstein, I., Las incertidumbres del saber, Gedisa, Barcelona, 2004, pp. 37-54.

${ }^{40}$ Ver Coloma, R., "El debate sobre los hechos en los procesos judiciales. ¿Qué inclina la balanza?”, en Accatino, D. (ed.). Formación y Valoración de la prueba en el proceso penal, Abeledo Perrot-LegalPublishing, Santiago, 2010, pp. 107, 115 y 116. 
construcción de lo probado, ya que los jueces conservan facultades para determinar el estatus de científico que se autoatribuye la disciplina, como también matiza o rechaza sus conclusiones al momento de valorar la prueba ${ }^{41}$.

Puede pensarse, entonces, que el carácter fuerte o débil de los AA en el contexto de la sana crítica depende del estatus que es reconocido a la disciplina proveedora de conocimientos. Así, por ejemplo, la lógica al menos en sus versiones más comprometidas con el razonamiento deductivo supone que sus reglas ejercen una función propia de argumentos no derrotables (son verdaderas para cualquier mundo posible y en consecuencia, muy fuertes); y las máximas de la experiencia, en cambio, operarán como argumentos débiles, en cuanto autorizan a identificar particularidades contextuales que autorizan a que en casos concretos no se aplique una cierta generalización ${ }^{42}$. El caso de los conocimientos científicos es más difícil, ya que en algunas situaciones operarán como argumentos fuertes (más allá de que el legislador se remita o no al examen de ADN, difícilmente serán dejadas de lado sus conclusiones) y en otras, como débiles (esto ocurre en el caso de informes sociales, psicológicos, etc.).

Para dirimir el estatus de fuerte o débil que es razonable conceder a estos AA derivados, puede tomarse en cuenta lo que Douglas Walton propone para los AA, en general. Según él, debiesen confluir varios factores para que el AA sea razonable de seguir, esto es, la aserción planteada cabe dentro del ámbito en el que el sujeto es experto, el sujeto es efectivamente un experto y no solo una mera celebridad en la disciplina, el sujeto es experto en el campo específico en el que está operando, debe haber una forma de resolver los desacuerdos con otros expertos, si hay prueba adicional disponible debe ser tenida en cuenta y lo que el experto diga debe ser correctamente interpretado por sus destinatarios, lo que supone que se exprese en un lenguaje asequible al lego ${ }^{43}$.

De lo que ha sido dicho puede concluirse que la sana crítica supone la inexistencia de AA originarios, pues estos se limitan a la prueba tasada ${ }^{44}$. Hay, en cambio, AA derivados, en la medida que la remisión sea hecha a sistema de producción de conocimientos cuyo valor socialmente aceptado sea independiente de la remisión que ha realizado el

${ }^{41}$ Cfr. Römkens, Renée. "Ambiguous Responsibilities: Law and Conflicting Expert Testimony on the Abused Woman Who Shot Her Sleeping Husband”, en Mertz, E., The Role of Social Science in Law, Ashgate, Aldershot, 2008, pp. 384-386, quien establece en un punto medio el poder del derecho y las disciplinas en el caso de expertos acerca del estado mental de los sujetos que participan en un juicio.

${ }^{42}$ Las máximas de la experiencia -al igual que el razonamiento económico- parte de supuestos de razonabilidad (y racionalidad) que no son predicables a todo evento de los individuos de carne y hueso, pues con cierta frecuencia nuestro comportamiento concreto no es explicable a partir de tales premisas (a veces somos poco razonables e irracionales).

43 Walton, D., "Reasoned use of expertise in argumentation”, en Argumentation 3, 1989, pp. 60-61.

${ }^{44}$ Si existiere esta clase de AA, el sistema de sana crítica no sería puro. 
legislador ${ }^{45}$. Debido a las dificultades en la ordenación de los sistemas proveedores de conocimientos, como también los desacuerdos que se producen al interior de estos, la sana crítica supone que normativamente no se determine, en términos absolutos, qué mecanismos de producción de conocimientos son (o no) derrotables, aun cuando las respuestas de disciplinas reconocidas por derecho propio lleguen a alcanzar el estatus de respuestas fuertes ${ }^{46}$. No es obstáculo en cambio que los AA sean débiles, ya que con ello el espacio de los tribunales permanece abierto a la aparición de mejores respuestas que las que por derivación han sido propuestas por el legislador. En otras palabras, la sana crítica supone la declinación del AA en sus vertientes más radicales, pero deja en pie la inercia que es propia de los AA débiles, siempre que estos sean derivados.

Por ello, las características del comportamiento humano y de algunas precariedades advertidas en los mecanismos de producción de conocimientos intersubjetivamente validados, la aplicación concreta de la sana crítica ha llevado a matizar las expectativas que en un comienzo pudieran haberse tenido respecto de ella. No es fácil ni deseable, el radical destierro del AA del espacio de los procesos judiciales. Sin embargo, esto no representa un fracaso de la sana crítica respecto de otras formas de aceptación de explicaciones en la arena judicial. La sana crítica al aprovechar los avances de quienes operan desde fuera de las fronteras reservadas a los abogados y a los jueces, es apta para provocar una mayor satisfacción respecto de las conclusiones extraíbles a partir de la prueba disponible en los procesos judiciales ${ }^{47}$.

\section{A MOdo DE CONCLUSIÓN}

Desde cierta perspectiva, con la irrupción de la sana crítica se esperaban satisfacer las pretensiones de eliminación de aquellos actos de la autoridad que forzaban a los jueces a

${ }^{45} \mathrm{Si}$, por ejemplo, el legislador obligaré a los jueces a ceñirse a los resultados que arroja el tarot, la ufología u otra disciplina que no sea socialmente reconocida como productora de conocimientos fiables, se produciría un alejamiento de la sana crítica, en razón de las conexiones que de ella se hacen con la valoración racional de la prueba. Esto lleva a que el sistema de valoración de la prueba se entienda estrechamente ligado al AA. Los jueces dirían algo como: ¡seguimos el tarot, solo porque el legislador lo ordena!. Esto difícilmente ocurriría con el juicio lógico o científico. Así, resultaría extravagante que un juez sostenga: ¡me ciño a la lógica y a las ciencias, solo porque el legislador lo ordena!

${ }^{46}$ Piénsese en el caso que el legislador, para ciertos efectos, decide que un determinado procedimiento de experto, siempre deberá prevalecer ante explicaciones alternativas. Piénsese, además, que en el momento en que dicta la regla, el procedimiento elegido (imaginemos examen de ADN) se encuentra en la cúspide del prestigio, por lo que incluso en caso de ausencia de tal regla un juez prudente lo utilizaría. Sin embargo, años después tal procedimiento es superado por otro mecanismo de producción de saberes que se demuestra como más fiable. En ese caso, la permanencia de la regla legal obligará al juez a ceñirse al examen de ADN, no obstante sus limitaciones. A contrario, si no hubiere existido tal regla es esperable que los jueces privilegien el nuevo mecanismo de producción de conocimientos.

${ }^{47}$ La inercia argumental no es obstáculo para operar según una forma de racionalidad que, según Rorty permite "examinar cualquier tema -religioso, literario o científico- de un modo que descarte el dogmatismo, la actitud defensiva y la radical indignación”. Rorty, Richard. "La ciencia como solidaridad", en Íd. Objetividad, relativismo y verdad. Barcelona: Paidós, 1996, p. 59. 
adoptar solo ciertas explicaciones a partir de la prueba disponible en los juicios. Parecía cumplirse con el sueño de Jeremy Bentham en favor de sistemas de prueba que fueren consistentes con la libertad imperante en los discursos científicos ${ }^{48}$. La representación indicada, sin embargo, adolecía de dos problemas. Por una parte, la razonabilidad del sueño benthamiano tenía algunas fracturas. Así, hay voces autorizadas que se han alzado en contra del proyecto de renunciar -en términos absolutos-a toda forma de regulación de la valoración de la prueba, pues hay espacios en que los mecanismos de producción de conocimientos tienen bastante poco que decir y, por tanto, resulta preferible que el legislador se haga cargo de distribuir los riesgos de error, no tanto (o exclusivamente) por la vía de imponer un estándar de prueba sino interviniendo en la admisibilidad, carga y valoración de las pruebas ${ }^{49}$. Por otra parte, desde un punto de vista descriptivo, el análisis acerca de las repercusiones de la sana crítica no habría reparado en el hecho que el legislador no se ha quedado totalmente al margen de la determinación de la forma en cómo debe valorarse la prueba. En ese sentido, el AA que tanto preocupaba al mundo de la ciencia y a muchos filósofos, dista de haber desaparecido del todo. El legislador, al menos en algunas de sus reglas ha ejercido un papel definicional estableciendo preferencias acerca de los sistemas productores de conocimiento a los que debe recurrirse para valorar la prueba. En vista de lo señalado podría concluirse que:

1. El ascenso de la sana crítica observado en épocas recientes no ha traído consigo una eliminación radical del AA, aun cuando ha representado una indudable declinación de este respecto a lo que antaño existía bajo los sistemas de prueba tasada.

2. A pesar de que el AA entra en tensión con las aspiraciones de control de racionalidad que suele hacerse recaer respecto de distintas formas de representar la realidad, resulta exagerado sostener que se encuentran en una relación de incompatibilidad.

3. El AA puede llegar a ser bastante útil para los efectos de hacer uso de la inercia en la argumentación que libera de tener que justificarlo todo.

4. Para un adecuado uso del AA en el espacio de la valoración de la prueba se requiere establecer algunas condiciones que ameritan ser estudiadas en profundidad $y$, que, en todo caso, ya han sido sugeridas principalmente en estudios sobre la prueba pericial. La más relevante apunta a que lo que sea planteado desde la disciplina o comunidad a la cual se reconoce autoridad permanecerá en pie, mientras no sea desafiada por otras formas de representación de la realidad que, en el caso

${ }^{48}$ Entre la muchas afirmaciones de Bentham en defensa de la prueba libre, puede destacarse la siguiente: "Encontrar, con relación a las pruebas, reglas infalibles, reglas que garanticen una resolución justa, es cosa rechazada en absoluto por la naturaleza misma de las cosas. Está demasiado arraigada en el espíritu humano la disposición a establecer reglas cuyo efecto sea el de hacer más probables las malas decisiones. De ahí que el mejor servicio que a este respecto pueda prestar un libre investigador de la verdad, se limita a poner en guardia al legislador y a los jueces contra esas reglas temerarias”. Bentham, J. Tratado de las pruebas judiciales, Vol. I, E.J.E.A., Buenos Aires, 1971, pp. 363-364.

${ }^{49}$ Bayón, J. C., "Epistemología, moral y prueba de los hechos: hacia un enfoque no benthamiano”, en Analisi e Diritto, 2008, pp. 15-34; Stein, A., Foundations of Evidence Law, Oxford University Press, Oxford, 2008, (Reimpresión), p. 12. 
concreto, aparezcan como mejor justificadas. Hasta que aquello no ocurra, podrá operarse en escenarios en que la inercia argumental corra en favor de aquellos argumentos que se encuentren en condiciones de exigir para sí el estatus de haber sido extraídos desde las reglas de la lógica, de la ciencia o del sentido común.

\section{BIBLIOGRAFÍA}

Alexy, R., Teoría de la argumentación jurídica. La teoría del discurso racional como teoría de la argumentación jurídica. Centro de Estudios Constitucionales, Madrid, 1989.

BAYón, J. C., "Epistemología, moral y prueba de los hechos: hacia un enfoque no benthamiano", en Analisi e Diritto, 2008, pp. 15-34.

Beccaria, C., Tratado de los delitos y las penas, $2^{\mathrm{a}}$ ed., Rosa Librero, París, 1828.

Bentham, J., Tratado de las pruebas judiciales, Vol. I, E.J.E.A., Buenos Aires, 1971.

Cappelletti, M., El proceso italiano en el cuadro de la contraposición "civil law" - "common law" Ien/ Íd. Proceso, ideologías, sociedad. Buenos Aires: E.J.E.A., 1974, pp. 315-361.

Cohen, L. J., "Freedom of proof", en Twining, W., Stein A. (eds.), Evidence and Proof. Darmouth, Aldershot, 1992, pp. 3-23.

Coloma, R., "El debate sobre los hechos en los procesos judiciales. ¿Qué inclina la balanza?", en Accatino, D. (ed.), Formación y Valoración de la prueba en el proceso penal, Abeledo PerrotLegalPublishing, Santiago, 2010, pp. 87-117.

Downs, A., An economic theory of democracy, Harper \&Row Publishers, New York, 1957.

ECO, U., Seis paseos por los bosques narrativos, Lumen, Barcelona, 1996.

Eemeren, F. v., Houtlosser, P., "Más sobre falacias como descarrilamientos de maniobras estratégicas: el caso de tu quoque”, en Santibáñez, C., Marafioti, R. (eds.), De las falacias: argumentación y comunicación, Biblos, Buenos Aires, 2008, pp. 37-51.

EkelöF, P., "Free Evaluation of Evidence", en Scandinavian Studies in Law, 1964, Vol. 8, pp. 47-66.

Feldman, R., "Evidentialism, higher-order evidence”, en Episteme, 2009, pp. 294-312.

Foucault, M., Los anormales, Fondo de Cultura Económica, Buenos Aires, 2011 (7ª reimpresión).

Fuentes, C., "La persistencia de la prueba legal en la judicatura de familia", en Revista de Derecho de la Universidad Católica del Norte, Año 18, No 1, 2011, pp. 119-145.

Giuliani, A., Il concetto de prova, Dott. A. Giuffrè Editore, Milano, 1961.,

Habermas, J., "Racionalidad del entendimiento. Aclaraciones al concepto de racionalidad comunicativa desde la teoría de los actos de habla”, en Íd., Verdad y justificación. Ensayos filosóficos, Trotta, Madrid, 2002, pp. 99-131.

Hacking, I., The emergence of probability, Cambridge University Press, 1975.

Hamblin, C. L., Fallacies, Vale Press, Virginia, 1970.

Kunn, Th., La estructura de las revoluciones científicas, $1^{a}$ edición (16 reimpresión), Fondo de Cultura Económica, Madrid, 1994.

Larroucau, J., "Res ipsa loquitur: Quien habla es el juez, no la cosa”, en Figueroa, G., Barros, E., Tapia, M. (coords.), Estudios de Derecho Civil VI, LegalPublishing, Santiago, 2011, pp. 491 a 519.

Montesquieu, C., Del espíritu de las leyes (libro VI, cap. XVII), Tecnos, Madrid, 1985.

PeArl, M., El Club Dante, Seix Barral, Barcelona, 2006.

Popper, K., La lógica de la investigación científica, Tecnos, Madrid, 1967 (reimpresión de la $1^{a}$ edición de 1962).

Raz, J., Razón práctica y normas, Centro de Estudios Constitucionales, Madrid, 1991. 
Römkens, R., “Ambiguous Responsibilities: Law and Conflicting Expert Testimony on the Abused Woman Who Shot Her Sleeping Husband”, en Mertz, E., The Role of Social Science in Law, Ashgate, Aldershot, 2008, pp. 399-435.

Rorty, R., "La ciencia como solidaridad", en Íd., Objetividad, relativismo y verdad. Paidós, Barcelona, 1996.

STEIn, A., "Against free proof”, en Israel Law Review, Vol. 31, 1997, pp. 573-589.

SOKAL, A. "El relativismo cognitivo en la filosofía de la ciencia", en Íd. Más allá de las imposturas intelectuales. Paidós, Barcelona, 2009, pp. 227-295.

Taruffo, M., La prueba de los hecho, Trotta, Madrid, 2000.

Tindale, C., "La falacia y la apelación a la autoridad", en Santibáñez, C., Marafioti, R. (eds.), De las falacias: argumentación y comunicación, Biblos, Buenos Aires, 2008, pp. 151-172.

Toulmin, S., Los usos de la argumentación, Península, Barcelona, 2007.

Ullmann-Margalit, E., Margalit, A., "Holding true and holding as true", en Synthese, Vol. 92, 1992, pp. 167-187.

Wallerstein, I., Las incertidumbres del saber, Gedisa, Barcelona, 2004.

Walton, D., "Reasoned use of expertise in argumentation", en Argumentation, 3, 1989, pp. 59-73.

ZÚÑIGA, Y., "Medida de protección terapéutica a favor de un menor (sentencias del tribunal de familia y de la corte de apelaciones de Valdivia)", (comentario), en Revista de Derecho de la Universidad Austral de Chile, Vol. XXII, No 1, julio de 2009, pp. 279-297. 